\title{
RESEARCH
}

Open Access

\section{Vascular resection for locally advanced pancreatic ductal adenocarcinoma: analysis of long-term outcomes from a single-centre series}

Claudio F. Feo ${ }^{1 *} \mathbb{D}$, Giulia Deiana ${ }^{1}$, Chiara Ninniri ${ }^{1}$, Giuseppe Cherchi ${ }^{1}$, Paola Crivelli ${ }^{2}$, Alessandro Fancellu ${ }^{1}$, Giorgio C. Ginesu ${ }^{1}$ and Alberto Porcu ${ }^{1}$

\begin{abstract}
Background: Pancreatic ductal adenocarcinoma (PDAC) is an aggressive malignancy with poor prognosis. Radical surgery is the best option for cure and, nowadays, it is performed by many surgeons also in cases of vascular infiltration. Whether this aggressive approach to a locally advanced PDAC produces a survival benefit is under debate. Most data in the literature come from retrospective comparative studies; therefore, it is still unclear if such an extensive surgery for an advanced cancer is justified.

Methods: A retrospective review of patients with PDAC treated at our institution over a 12-year period was performed. Data concerning patients' characteristics, operative details, postoperative course, and long-term survival were retrieved from prospective databases and analysed. Factors associated with poor survival were assessed via Cox regression analysis.

Results: A total of 173 patients with PDAC were included in the analysis, 41 subjects underwent pancreatectomy with vascular resection for locally advanced disease, and in 132 patients, only a pancreatic resection was undertaken. Demographics, major comorbidities, and tumour characteristics were similar between the two groups. Length of surgery $(P=0.0006)$, intraoperative blood transfusions $(P<0.0001)$, and overall complications $(P<0.0001)$ were significantly higher in the vascular resection group. Length of hospital stay $(P=0.684)$ and 90 -day mortality $(P=0.575)$ were comparable between groups. Overall median survival $(P=0.717)$ and survival rates at 1,3 , and 5 years ( $P=0.964, P=0.500$, and $P=0.445$, respectively) did not differ significantly between groups. Age $\geq 70$ years and postoperative complications were independent predictors of lower survival.

\footnotetext{
*Correspondence: cffeo@uniss.it

'Unit of General Surgery 2, Department of Medical, Surgical and

Experimental Sciences, University of Sassari, Viale San Pietro 43, 07100 Sassari, Italy

Full list of author information is available at the end of the article
}

(c) The Author(s). 2021 Open Access This article is licensed under a Creative Commons Attribution 4.0 International License, which permits use, sharing, adaptation, distribution and reproduction in any medium or format, as long as you give appropriate credit to the original author(s) and the source, provide a link to the Creative Commons licence, and indicate if changes were made. The images or other third party material in this article are included in the article's Creative Commons licence, unless indicated otherwise in a credit line to the material. If material is not included in the article's Creative Commons licence and your intended use is not permitted by statutory regulation or exceeds the permitted use, you will need to obtain permission directly from the copyright holder. To view a copy of this licence, visit http://creativecommons.org/licenses/by/4.0/. The Creative Commons Public Domain Dedication waiver (http://creativecommons.org/publicdomain/zero/1.0/) applies to the data made available in this article, unless otherwise stated in a credit line to the data. 
(Continued from previous page)

Conclusions: Our study confirms that pancreatectomy with vascular resection for a locally advanced PDAC is a complex operation associated with a significant longer operating time that may increase morbidity; however, in selected patients, R0 margins can be obtained with an acceptable long-term survival rate. Older patients are less likely to benefit from surgery.

Keywords: Pancreatic ductal adenocarcinoma, Pancreatic surgery, Venous infiltration, Arterial infiltration, Prognosis, Survival

\section{Introduction}

Pancreatic ductal adenocarcinoma (PDAC) is a very aggressive malignancy with poor long-term prognosis. About $80-85 \%$ of patients have a locally advanced disease at diagnosis $[1,2]$ and the 5-year survival rate is approximately $5-7 \%$ [3, 4]. Radical surgical resection is the best option for cure; however, the presence of major vessel invasion is usually considered a criterion for unresectability.

According to the National Comprehensive Cancer Network (NCCN) guidelines [5], a tumour involving the arterial and/or the portal/mesenteric axis is considered a borderline resectable pancreatic cancer (BRPC). However, this is an intermediate category including locally advanced tumours that ranges from resectable to unresectable lesions [6-8]. The vessels involved and tumour extension into the vessel wall may vary consistently; therefore, vascular resection and reconstruction may be achieved by different methods: partial resection with direct closure of the defect, segmental resection with end-to-end anastomosis, segmental resection with interposed venous/artificial graft, or resection and reconstruction of multiple vessels $[9,10]$. A recent international consensus statement [11] on the definition of BRPC has considered, besides the anatomic relationship between tumour and vessels, also biological and conditional dimensions. Biological features included suspicion for distant or lymph node metastases, whereas conditional factors comprised patient's performance status.

Improvements in the perioperative care have resulted in comparable mortality and morbidity rates between resectable and BRPC patients [12]. Venous (portal vein, superior mesenteric vein) infiltration is encountered more frequently than arterial (hepatic artery, celiac trunk, superior mesenteric artery) invasion; nonetheless, R0 resection may be achieved by an experienced hepatobiliary surgeon in both cases. Whether this aggressive surgical approach to a locally advanced PDAC produces a long-term survival benefit is still unclear.

The aim of our study was to compare the oncologic outcomes of patients with locally advanced PDAC who did and those who did not undergo vascular resection. The prognostic factors were also analysed to determine which features were associated with a poor prognosis.

\section{Methods \\ Study population}

Data on all pancreatic resections for diagnosis of PDAC performed in our academic hospital from January 2008 to January 2020 were collected from a prospectively maintained database. Vascular resection (venous and/or arterial) was performed when tumour infiltration was suspected based on the radiologic and/or intraoperative evaluation. Demographic, preoperative, intraoperative, and postoperative data were retrieved and analysed. Patients' characteristics included age, sex, body mass index (BMI), American Society of Anesthesiologists (ASA) score [13], comorbidities, and tumour stage. Preoperative abdominal computed tomography (CT) scan of each patient who underwent vascular resection was reviewed by a radiologist to determine the degree of tumour contact between the tumour and the vessel, less or more than $180^{\circ}$.

The study was approved by our institutional review board, and informed consent was obtained from all patients prior to each procedure.

\section{Surgical technique}

All procedures were performed by the same skilled hepatobiliary surgeon. Depending on the tumour location, a standard Whipple or Traverso-Longmire pancreaticoduodenectomy, a distal splenopancreatectomy, or a total pancreatectomy was performed in all patients. A Roux-en-Y jejunal loop reconstruction was routinely undertaken with an end-to-end telescopic pancreaticojejunostomy and an end-to-side hepaticojejunostomy, both protected by internal drainages. Vascular resection was performed en-bloc with the pancreas when needed to obtain an R0 margin. Vessel reconstruction was undertaken with either a direct running suture, an autologous venous patch (great saphenous vein), or interposition of an autologous venous segment (superficial femoral vein) depending on the length of the resected vessel. All patients received intravenous heparin prior to vessel clamping and then prophylactic subcutaneous low-molecular-weight heparin for 1 month from the operation. Intraabdominal drainages were routinely placed near either the pancreatico-enteric or the bilio-enteric anastomoses. 


\section{Histopathological examination}

Intraoperative frozen sections were performed on the hepatic duct and the pancreatic stump in all cases, and resection was extended until a negative margin could be achieved or the operation was changed to a total pancreatectomy. Definitive histopathological reports were reviewed to determine the TNM (Tumour-Node-Metastasis) stage, according to the American Joint Committee on Cancer 7th edition [14]. Pathological confirmation of vessel wall infiltration was routinely performed in all cases of vascular resection. Data on tumour size, lymph node involvement, and perineural and lymphovascular invasion were retrieved and analysed.

\section{Follow-up protocol}

Postoperative complications were graded according to the Clavien-Dindo classification [15]. Definitions from the International Study Group of Pancreatic Surgery (ISGPF) [16-18] were used to evaluate specific complication of pancreas surgery, like postoperative pancreatic fistula (POPF), delayed gastric emptying, and haemorrhage. Mortality was calculated at 90 days from the surgical operation. Follow-up data were collected by an oncologist. All patients underwent clinical, laboratory, and imaging tests at 3, 6, and 12 months postoperatively. Oncological outcomes were obtained from electronic hospital records.

\section{Statistical analysis}

Continuous variables were expressed as mean and standard deviation or median and interquartile range (IQR). Categorical variables were reported as count and percentages. Chi-square test, Student's $t$-test, or MannWhitney $U$-test was used as appropriate, and a $P$ value up to 0.05 was considered statistically significant. Survival curves were determined using the Kaplan-Meier method including the log-rank test. The Cox regression model was applied for uni- and multivariate analyses to identify features associated with worst outcomes. Statistical analyses were performed by using SPSS 20 for Windows software (IBM Corp, Armonk, NY, USA).

\section{Results}

From January 2008 to January 2020, a total of 173 patients underwent pancreatic resection for PDAC at our institution. There were 89 females, mean age 68.7 years (range 23-87). In 41 (23.7\%) cases, a vascular resection $(\mathrm{VR}+)$ was necessary whereas in the remaining 132 subjects (76.3\%) no vessel resection (VR-) was performed. Of the 41 patients in the $\mathrm{VR}+$ group, 37 underwent isolated venous resection, 2 isolated arterial resection, and 2 combined venous/arterial resection.

Patients' details are presented in Table 1. There were no significant differences between groups in demographics,

Table 1 Patients' characteristics

\begin{tabular}{|c|c|c|c|c|}
\hline & Overall ( $n=173)$ & VR- group ( $n=132)$ & VR+ group $(n=41)$ & $P$-value \\
\hline Age (years), mean & $68.7 \pm 10.8$ & $68.6 \pm 11.1$ & $69 \pm 10.0$ & 0.850 \\
\hline Male/female & $84 / 89$ & $67 / 65$ & $17 / 24$ & 0.298 \\
\hline BMI $\left(\mathrm{kg} / \mathrm{m}^{2}\right)$, mean & $25.9 \pm 3.9$ & $26.6 \pm 3.9$ & $23 \pm 3.8$ & 0.063 \\
\hline \multicolumn{5}{|l|}{ ASA class } \\
\hline |-|| (\%) & $85(49.1)$ & $61(46.2)$ & $24(58.5)$ & 0.168 \\
\hline III (\%) & $88(50.9)$ & $71(53.8)$ & $17(41.5)$ & 0.168 \\
\hline \multicolumn{5}{|l|}{ Comorbidities } \\
\hline Diabetes (\%) & $24(13.9)$ & $16(12.1)$ & $8(19.5)$ & 0.232 \\
\hline Cardiovascular disease (\%) & $25(14.5)$ & $20(15.2)$ & $5(12.2)$ & 0.638 \\
\hline COPD (\%) & $2(1.2)$ & $2(1.5)$ & 0 & 0.428 \\
\hline Obstructive jaundice (\%) & $43(24.9)$ & $25(18.9)$ & $18(43.9)$ & 0.001 \\
\hline Preoperative biliary drainage (\%) & $20(11.6)$ & $10(7.6)$ & $10(24.4)$ & 0.003 \\
\hline \multicolumn{5}{|l|}{ Tumour stage } \\
\hline I (\%) & $47(27.2)$ & $39(29.5)$ & $8(19.5)$ & 0.207 \\
\hline II (\%) & $70(40.5)$ & $55(41.7)$ & $15(36.6)$ & 0.563 \\
\hline III (\%) & $47(27.2)$ & $32(24.2)$ & $15(36.6)$ & 0.121 \\
\hline IV (\%) & $9(5.2)$ & $6(4.5)$ & $3(7.3)$ & 0.485 \\
\hline \multicolumn{5}{|l|}{ Degree of tumour contact at $C T$} \\
\hline$<180^{\circ}(\%)$ & $31(17.9)$ & - & $31(75.6)$ & \\
\hline$>180^{\circ}(\%)$ & $10(5.8)$ & - & $10(24.4)$ & \\
\hline
\end{tabular}

$B M I$ body mass index, ASA American Society of Anesthesiologists, COPD chronic obstructive pulmonary disease, CT computed tomography 
major comorbidities, and tumour characteristics. In the $\mathrm{VR}+$ group, obstructive jaundice was more frequent $(P=0.001)$ and a greater number of patients underwent preoperative biliary drainage $(P=0.003)$. Abdominal CT scan review of the $41 \mathrm{VR}+$ patients showed the presence of tumour abutment greater than $180^{\circ}$ in $24.4 \%$ of cases.

Operative and postoperative data are summarised in Table 2. Length of surgery was significantly longer in the VR+ group (343.9 versus $295.1 \mathrm{~min}, P=0.006$ ), but no significant difference between groups regarding the type of operation performed except for total pancreatectomies $(P=0.005)$. Duration of ICU stay (1.4 versus 0.7 days, $P=0.187)$ and length of hospital stay (18.3 versus 18.9 days, $P=0.684$ ) were comparable in the two groups. Intraoperative blood transfusions (53.7 versus 19.8\%) and overall complications (61 versus $23.5 \%$ ) were significantly higher in the VR+ cases $(P<0.0001$, in both cases). A POPF occurred in $9.8 \%$ and $11.4 \%$ of the VR+ and VR - patients, respectively $(P=0.774)$. Delayed gastric emptying (7.3 versus $1.5 \%)$, postoperative haemorrhage (14.6 versus $2.3 \%$ ), and reoperation (14.6 versus $5.3 \%$ ) were observed more frequently in the $\mathrm{VR}+$ patients as compared to the VR- cases $(P=0.053, P=0.002$, and $P=$ 0.048 , respectively). Mortality at 90 days from the operation was 14.6 and $11.4 \%$ in the VR+ and VR-groups, respectively $(P=0.575)$.

Oncological outcomes are shown in Table 3 and Fig. 1. Mean tumour size (3.5 versus $2.8 \mathrm{~cm}$ ) and perineural infiltration (61 versus $43.2 \%$ ) were significantly greater in the $\mathrm{VR}+$ cases $(P=0.005$ and $P=0.046$, respectively). However, lymphovascular invasion (29.3 versus $18.2 \%, P=0.127$ ),

Table 2 Operative and postoperative details

\begin{tabular}{|c|c|c|c|c|}
\hline & Overall $(n=173)$ & VR- group ( $n=132)$ & VR+ group $(n=41)$ & $P$-value \\
\hline Operative time (minutes), mean & $309.2 \pm 93.2$ & $295.1 \pm 96.3$ & $343.9 \pm 75.6$ & 0.006 \\
\hline \multicolumn{5}{|l|}{ Type of operation } \\
\hline Whipple PD (\%) & $53(30.6)$ & $43(32.6)$ & $10(24.4)$ & 0.321 \\
\hline Traverso-Longmire PD (\%) & $65(37.6)$ & $52(39.4)$ & $13(31.7)$ & 0.375 \\
\hline Distal splenopancreatectomy (\%) & $25(14.5)$ & $20(15.2)$ & $5(12.2)$ & 0.638 \\
\hline Total pancreatectomy (\%) & $30(17.3)$ & $17(12.9)$ & $13(31.7)$ & 0.005 \\
\hline \multicolumn{5}{|l|}{ Type of vascular resection } \\
\hline Venous (\%) & $37(21.4)$ & - & $37(90.2)$ & \\
\hline Arterial (\%) & $2(1.2)$ & - & $2(4.9)$ & \\
\hline Arteria/venous (\%) & $2(1.2)$ & - & $2(4.9)$ & \\
\hline \multicolumn{5}{|l|}{ Type of vessel reconstruction } \\
\hline Direct suture (\%) & $32(18.5)$ & - & $32(78)$ & \\
\hline Autologous venous patch (\%) & $1(0.6)$ & - & $1(2.4)$ & \\
\hline Autologous venous segment (\%) & $8(4.6)$ & - & $8(19.5)$ & \\
\hline Intraoperative blood transfusion (\%) & $48(27.7)$ & $26(19.7)$ & $22(53.7)$ & $<0.0001$ \\
\hline ICU stay (days), mean & $1 \pm 2.3$ & $0.7 \pm 1.6$ & $1.4 \pm 3.0$ & 0.187 \\
\hline \multicolumn{5}{|l|}{ Clavien-Dindo class } \\
\hline I (\%) & $10(26)$ & $7(28)$ & $3(19.5)$ & 0.629 \\
\hline II (\%) & $30(17.3)$ & $15(11.4)$ & $15(36.6)$ & 0.000 \\
\hline III (\%) & $14(8.1)$ & $8(6.1)$ & $6(14.6)$ & 0.079 \\
\hline IV (\%) & $2(1.2)$ & $1(0.8)$ & $1(2.4)$ & 0.379 \\
\hline Overall complications & $56(32.4)$ & $31(23.5)$ & $25(61)$ & $<0.0001$ \\
\hline \multicolumn{5}{|l|}{ Pancreas-specific complications } \\
\hline POPF (\%) & $19(11)$ & $15(11.4)$ & $4(9.8)$ & 0.774 \\
\hline Haemorrhage (\%) & $9(5.2)$ & $3(2.3)$ & $6(14.6)$ & 0.002 \\
\hline Delayed gastric emptying (\%) & $5(2.9)$ & $2(1.5)$ & $3(7.3)$ & 0.053 \\
\hline Reoperation (\%) & $13(7.5)$ & $7(5.3)$ & $6(14.6)$ & 0.048 \\
\hline Hospital stay (days), mean & $18.6 \pm 12.6$ & $18.9 \pm 14.0$ & $18.3 \pm 10.5$ & 0.684 \\
\hline 90-day mortality (\%) & $21(12.1)$ & $15(11.4)$ & $6(14.6)$ & 0.575 \\
\hline
\end{tabular}

$P D$ pancreaticoduodenectomy, ICU intensive care unit, POPF postoperative pancreatic fistula 
Table 3 Oncological data

\begin{tabular}{|c|c|c|c|c|}
\hline & Overall $(n=173)$ & VR- group $(n=132)$ & VR+ group $(n=41)$ & $P$-value \\
\hline Tumour size $(\mathrm{cm})$, mean & $3.1 \pm 1.2$ & $2.8 \pm 1.0$ & $3.5 \pm 1.2$ & 0.005 \\
\hline Lymphovascular invasion (\%) & $36(20.8)$ & $24(18.2)$ & $12(29.3)$ & 0.127 \\
\hline Perineural invasion (\%) & $82(47.4)$ & $57(43.2)$ & $25(61)$ & 0.046 \\
\hline Lymph node ratio, mean & $0.14 \pm 0.18$ & $0.14 \pm 0.19$ & $0.15 \pm 0.14$ & 0.795 \\
\hline Positive resection margins (\%) & $13(7.5)$ & $9(6.8)$ & $4(9.8)$ & 0.533 \\
\hline Pathological vessel infiltration (\%) & $32(18.5)$ & - & $32(78)$ & \\
\hline \multicolumn{5}{|l|}{ Survival } \\
\hline Overall (months), median & $\begin{array}{l}17.7 \\
(0.1-148.6)\end{array}$ & $\begin{array}{l}18.4 \\
(0.1-148.6)\end{array}$ & $\begin{array}{l}15.4 \\
(0.9-101.7)\end{array}$ & 0.717 \\
\hline 1 year $(\%)$ & $106(61.3)$ & $81(61.4)$ & $25(61)$ & 0.964 \\
\hline 3 years (\%) & $36(20.8)$ & $29(22)$ & $7(17.1)$ & 0.500 \\
\hline 5 years (\%) & $23(13.3)$ & $19(14.4)$ & $4(9.8)$ & 0.445 \\
\hline
\end{tabular}

lymph node ratio ( 0.14 versus $0.13, P=0.795)$, and positive resection margins ( 9.8 versus $6.8 \%, P=0.533$ ) did not differ significantly between groups. Pathological confirmation of vessel wall infiltration was found in 32 of the 41 (78\%) $\mathrm{VR}+$ cases. Overall median survival was 15.4 versus 18.4 months in the VR+ and VR- patients, respectively $(P=$ 0.717). Median survival in the 37 patients who underwent isolated venous resection was 17 months, whereas in the 4 patients who underwent arterial resection ( 2 arterial +2 arterial/venous) it was 5 months $(P=0.180)$. Survival rates at 1,3 , and 5 years were $61,17.1$, and $9.8 \%$ in the VR+ group, and $61.4,22$, and $14.4 \%$ in the VR- patients, respectively ( $P=0.964, P=0.500$, and $P=0.445$, respectively).

At multivariate analysis (Table 4 ), age $\geq 70$ years (HR $1.59,95 \%$ CI 1.05-2.43) and postoperative complications (HR 2.08, 95\% CI 1.20-3.60) were independent predictors of lower survival. Tumour size $\geq 3 \mathrm{~cm}$, lymphovascular invasion, perineural infiltration, positive resection margins, and vascular resection were not predictors of overall survival.

\section{Survival distribution function}

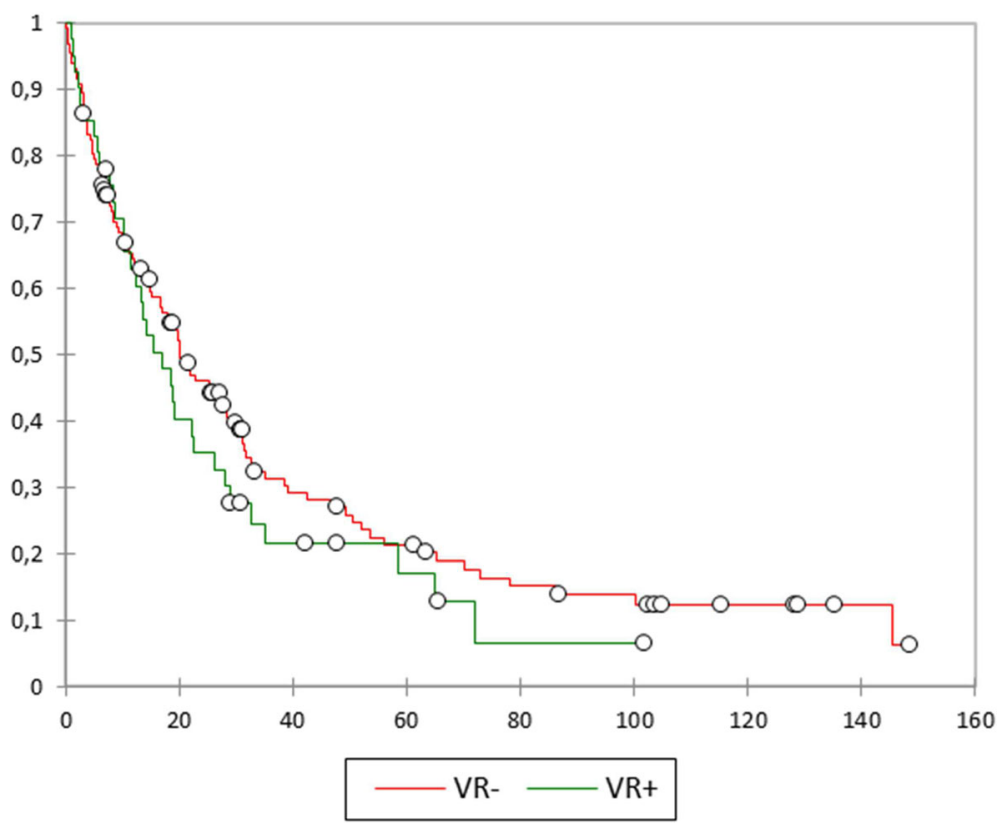

Fig. 1 Kaplan-Meier survival curves. Overall survival $(P=0.717), V R-$ (red line) vs. VR+ (green line) group 
Table 4 Uni- and multivariate analysis

\begin{tabular}{lll}
\hline & Univariate & \multicolumn{1}{c}{$\begin{array}{c}\text { Multivariate } \\
\text { HR (95\% Cl) }\end{array}$} \\
\hline Age $\geq 70$ years & Patients (MST) P-value & $\mathbf{1 . 5 9 ( 1 . 0 5 - 2 . 4 3 )}$ \\
Male gender & $90(30.03) \mathbf{0 . 0 1 1}$ & $1.39(0.90-2.13)$ \\
Whipple PD & $84(33.96) 0.939$ & $1.32(0.86-2.05)$ \\
Postoperative complications & $53(28.49) 0.399$ & $\mathbf{2 . 0 8}(\mathbf{1 . 2 0 - 3 . 6 0 )}$ \\
Tumour size $\geq 3 \mathrm{~cm}$ & $56(20.30) \mathbf{0 . 0 0 9}$ & $1.34(0.87-2.07)$ \\
Lymphovascular invasion & $36(38.49) 0.223$ & $0.81(0.44-1.47)$ \\
Perineural invasion & $36(37.09) 0.481$ & $1.47(0.89-2.43)$ \\
Positive resection margins & $82(30.13) 0.545$ & $0.59(0.26-1.32)$ \\
Vascular resection & $13(26.62) 0.512$ & $0.83(0.48-1.45)$ \\
\hline
\end{tabular}

$P D$ pancreaticoduodenectomy, MST median survival time (months), $H R$ hazard ratio, $\mathrm{Cl}$ confidence interval

\section{Discussion}

Previous studies have shown that pancreaticoduodenectomy (PD) with vascular resection is associated with a greater tumour size, higher R1 resection rate, more frequent perineural or lymph node infiltration, and worse survival [12, 19]. However, in other comparative reports, these poorer outcomes were not observed [20-24], and a definitive conclusion cannot be made. In recent years, many surgeons all over the world perform a vascular resection in cases of locally advanced PDAC in order to achieve R0 margins. Most data in the literature come from retrospective comparative studies; therefore, it is still unclear if such an aggressive approach to an advanced cancer is justified.

In our study, we retrospectively reviewed a prospective series of 173 patients with PDAC, 41 subjects underwent pancreatectomy with vascular resection for locally advanced disease, and in 132 patients, only a pancreatic resection was undertaken. Patients' characteristics and operative and postoperative data were similar between groups. The operative time as a consequence of the additional procedure performed was significantly longer in the VR+ group. Despite a higher morbidity in the VR+ patients, there was no significant difference in length of stay and mortality between groups. Preoperative biliary drainage was necessary in a higher number of VR+ cases, and this may be responsible for the significantly increased complication rate in this group of patients [25]. A higher incidence of complications after biliary drainage has been observed also in two recent metaanalyses [26, 27]; however, the delay in surgery related to the stenting procedure does not seem to affect overall survival $[28,29]$. Furthermore, other meta-analyses have found opposite results. Sun et al. [30] reported no significant difference in postoperative morbidity and mortality in patients with obstructive jaundice who underwent preoperative biliary stenting. Surprisingly, Moole et al. [31] observed significantly less major adverse events in patients undergoing preoperative biliary drainage compared to those undergoing direct surgery. In all these meta-analyses, the majority of data come from retrospective studies and results should be regarded with caution. The role of preoperative biliary drainage on postoperative outcomes probably needs to be further investigated in future studies.

In most series, only about two-thirds of patients who underwent vascular resection had a histologically proven invasion, whereas in our material this rate was slightly higher with $78 \%$ of patients with confirmed vessel wall infiltration. However, the presence of histological proven venous wall invasion in patients undergoing PD for pancreatic cancer has been reported to affect disease-free and overall survival with conflicting results [32-35]. Of note is that also the depth of wall invasion does not seem to influence survival rates. Roch et al. [36] analysed a series of 567 patients who underwent PD for PDAC, and segmental vein resection was performed in 90 cases. The extent of venous wall infiltration did not significantly influence overall survival and disease-free survival. Moreover, in a report from Hoshimoto et al. [37], the depth of vessel invasion did not impact overall survival in a series of 122 pancreatic cancer patients. In another study from Ravikumar et al. [38], a series of 229 patients undergoing PD with portal vein resection was analysed and no significant difference in median survival in patients with superficial, deep, or no histological involvement was observed. Finally, Addeo et al. [39] evaluated retrospectively 181 PDs and venous resection was performed in 91 cases. There was no difference in survival between patients with or without venous infiltration, but invasion of the intima was found to be an independent predictor of poor survival.

Previous research found that larger tumour size is correlated with reduced overall survival $[10,40]$. Greater tumours are more likely associated to perineural infiltration and lymph node involvement that can explain a 
more aggressive behaviour. In our series, patients who underwent vascular resection had a significant larger tumour size and higher perineural infiltration rate, and this may justify the presence of venous/arterial wall invasion that required a more complex operation with a prolonged operating time. We also found in the VR+ cases a trend toward more frequent lymphovascular invasion and $\mathrm{R} 1$ resection, but these parameters were not statistically significant. Despite these aggressive features in the $\mathrm{VR}+$ group, overall survival and long-term survival rates were comparable in the two groups, and these findings are similar to what was reported by others [20-24, 41].

Arterial infiltration (hepatic artery, celiac trunk, superior mesenteric artery) in patients with advanced PDAC is usually considered a contraindication for surgical resection because of increased morbidity and mortality [42, 43]. In fact, early in our experience, the four patients who underwent arterial resection had a much lower median survival compared to those undergoing isolated venous resection, though not significant. A very recent review from the French National Institute of Cancer [44] suggested that arterial resection may be proposed in selected patients only after response to neoadjuvant treatment.

The limitations associated with the present study include its retrospective nature and a limited number of patients. However, this is a single-centre series of consecutive patients who were operated by the same experienced hepatobiliary surgeon and they all received the same postoperative care protocol. Another limit is the absence of preoperative chemotherapy, but our survival rates were comparable between groups particularly if we consider patients who underwent isolated venous resection. Therefore, despite a higher morbidity, upfront surgery in selected patients with vascular involvement can be offered to improve survival.

\section{Conclusions}

Our study confirms that pancreatectomy with vascular resection for a locally advanced PDAC is a complex operation associated with a significant longer operating time that may increase morbidity; however, in selected patients, R0 margins can be obtained with an acceptable long-term survival rate. Older patients are less likely to benefit from surgery. Further studies are warranted to better define the criteria for patient selection.

\footnotetext{
Abbreviations

PDAC: Pancreatic ductal adenocarcinoma; NCCN: National Comprehensive Cancer Network; BRPC: Borderline resectable pancreatic cancer; BMI: Body mass index; ASA: American Society of Anesthesiology; CT: Computed tomography; TNM: Tumour-Node-Metastasis; ISGPF: International Study Group for Pancreatic Surgery; POPF: Postoperative pancreatic fistula; ICU: Intensive care unit; HR: Hazard ratio; Cl: Confidence interval; PD: Pancreaticoduodenectomy
}

Authors' contributions

FCF: writing and draft preparation; FCF and DG: methodology and data analysis; NC, CG, and CP: data collection and editing; FA, GGC, and PA: supervision and critical review. The authors read and approved the final manuscript.

\section{Funding}

No funds or grants have been received for this study.

\section{Availability of data and materials}

The datasets used and/or analysed during the current study are available from the corresponding author on reasonable request.

\section{Declarations}

Ethics approval and consent to participate

Ethical approval was waived by the local institutional board (Comitato Etico, AOU Sassari) in view of the retrospective nature of the study, and informed consent was obtained from all patients prior to each procedure.

\section{Consent for publication}

All authors agree to publish the paper.

\section{Competing interests}

The authors declare that they have no competing interests.

\section{Author details}

${ }^{1}$ Unit of General Surgery 2, Department of Medical, Surgical and Experimental Sciences, University of Sassari, Viale San Pietro 43, 07100 Sassari, Italy. ${ }^{2}$ Unit of Radiology, Department of Medical, Surgical and Experimental Sciences, University of Sassary, Viale San Pietro 10, Sassari 07100, Italy.

Received: 16 January 2021 Accepted: 12 April 2021

Published online: 18 April 2021

\section{References}

1. Van Veldhuisen E, Van den Oord C, Brada LJ, Walma S, Vogel JA, Wilmink JW, et al. Locally advanced pancreatic cancer: work-up, staging, and local intervention strategies. Cancers. 2019;11(7):976.

2. Ruarus A, Vroomen L, Puijk R, Scheffer H, Meijerink M. Locally advanced pancreatic cancer: a review of local ablative therapies. Cancers. 2018;10(1): 16. https://doi.org/10.3390/cancers10010016.

3. Bray F, Ferlay J, Soerjomataram I, Siegel RL, Torre LA, Jemal A. Global cancer statistics 2018: GLOBOCAN estimates of incidence and mortality worldwide for 36 cancers in 185 countries. CA Cancer J Clin. 2018;68(6):394-424. https://doi.org/10.3322/caac.21492.

4. Rawla P, Sunkara T, Gaduputi V. Epidemiology of pancreatic cancer: global trends, etiology and risk factors. World J Oncol. 2019;10(1):10-27. https://doi. org/10.14740/wjon1166.

5. Tempero MA, Malafa MP, Al-Hawary M, Asbun H, Bain A, Behrman SW, et al. Pancreatic adenocarcinoma, version 2.2017, NCCN clinical practice guidelines in oncology. J Natl Compr Cancer Netw. 2017;15(8):1028-61.

6. Varadhachary GR, Tamm EP, Abbruzzese JL, Xiong HQ, Crane $\mathrm{CH}$, Wang $\mathrm{H}$, et al. Borderline resectable pancreatic cancer: definitions, management, and role of preoperative therapy. Ann Surg Oncol. 2006 Aug;13(8):1035-46. https://doi.org/10.1245/ASO.2006.08.011

7. Callery MP, Chang KJ, Fishman EK, Talamonti MS, William Traverso L, Linehan DC. Pretreatment assessment of resectable and borderline resectable pancreatic cancer: expert consensus statement. Ann Surg Oncol. 2009;16(7):1727-33. https://doi.org/10.1245/s10434-009-0408-6.

8. Bockhorn M, Uzunoglu FG, Adham M, Imrie C, Milicevic M, Sandberg AA, et al. Borderline resectable pancreatic cancer: a consensus statement by the International Study Group of Pancreatic Surgery (ISGPS). Surgery. 2014; 155(6):977-88

9. Gong $Y$, Zhang L, He T, Ding J, Zhang H, Chen G, et al. Pancreaticoduodenectomy combined with vascular resection and reconstruction for patients with locally advanced pancreatic cancer: a multicenter, retrospective analysis. PLoS One. 2013;8(8):e70340. https://doi. org/10.1371/journal.pone.0070340.

10. Zhu J, Li X, Kou J, Ma J, Li L, Fan H, et al. Proposed Chaoyang vascular classification for superior mesenteric-portal vein invasion, resection, and 
reconstruction in patients with pancreatic head cancer during pancreaticoduodenectomy - a retrospective cohort study. Int J Surg. 2018; 53:292-7. https://doi.org/10.1016/j.ijsu.2018.04.011.

11. Isaji S, Mizuno S, Windsor JA, Bassi C, Fernández-Del Castillo C, Hackert T, et al. International consensus on definition and criteria of borderline resectable pancreatic ductal adenocarcinoma 2017. Pancreatology. 2018; 18(1):2-11. https://doi.org/10.1016/j.pan.2017.11.011.

12. Fancellu A, Petrucciani N, Porcu A, Deiana G, Sanna V, Ninniri C, et al. The impact on survival and morbidity of portal-mesenteric resection during pancreaticoduodenectomy for pancreatic head adenocarcinoma: a systematic review and meta-analysis of comparative studies. Cancers. 2020; 12(7):1976. https://doi.org/10.3390/cancers12071976.

13. Doyle DJ, Goyal A, Bansal P, Garmon EH. American Society of Anesthesiologists classification:: StatPearls Publishing; 2020.

14. Edge SB, Byrd DR, Compton CC, Fritz AG, Greene FL, Trotti A. AJCC cancer staging manual. 7th ed. New York: Springer; 2010.

15. Dindo D, Demartines N, Clavien PA. Classification of surgical complications: a new proposal with evaluation in a cohort of 6336 patients and results of a survey. Ann Surg. 2004;240(2):205-13. https://doi.org/10.1097/01.sla.0000133 083.54934.ae.

16. Bassi C, Dervenis C, Butturini G, Fingerhut A, Yeo C, Izbicki J, et al. Postoperative pancreatic fistula: an international study group (ISGPF) definition. Surgery. 2005; 138(1):8-13. https://doi.org/10.1016/j.surg.2005.05.001.

17. Wente MN, Veit JA, Bassi C, Dervenis C, Fingerhut A, Gouma DJ, et al. Postpancreatectomy hemorrhage (PPH): an International Study Group of Pancreatic Surgery (ISGPS) definition. Surgery. 2007;142(1):20-5. https://doi. org/10.1016/j.surg.2007.02.001.

18. Wente MN, Bassi C, Dervenis C, Fingerhut A, Gouma DJ, Izbicki JR, et al. Delayed gastric emptying (DGE) after pancreatic surgery: a suggested definition by the International Study Group of Pancreatic Surgery (ISGPS). Surgery. 2007;142(5):761-8. https://doi.org/10.1016/j.surg.2007.05.005.

19. Bell R, Ao BT, Ironside N, Bartlett A, Windsor JA, Pandanaboyana S. Metaanalysis and cost-effective analysis of portal-superior mesenteric vein resection during pancreatoduodenectomy: impact on margin status and survival. Surg Oncol. 2017;26(1):53-62. https://doi.org/10.1016/j.suronc.201 6.12.007.

20. Worni M, Castleberry AW, Clary BM, Gloor B, Carvalho E, Jacobs DO, et al. Concomitant vascular reconstruction during pancreatectomy for malignant disease: a propensity score-adjusted, population-based trend analysis involving 10,206 patients. JAMA Surg. 2013;148(4):331-8. https://doi.org/10.1 001/jamasurg.2013.1058

21. Kelly KJ, Winslow E, Kooby D, Lad NL, Parikh AA, Scoggins CR, et al. Vein involvement during pancreaticoduodenectomy: is there a need for redefinition of "borderline resectable disease"? J Gastrointest Surg. 2013; 17(7):1209-17. https://doi.org/10.1007/s11605-013-2178-5.

22. Ravikumar R, Sabin C, Abu Hilal M, Bramhall S, White S, Wigmore S, et al. Portal vein resection in borderline resectable pancreatic cancer: a United Kingdom multicenter study. J Am Coll Surg. 2014;218(3):401-11. https://doi. org/10.1016/j.jamcollsurg.2013.11.017.

23. Murakami Y, Satoi S, Motoi F, Sho M, Kawai M, Matsumoto I, et al. Portal or superior mesenteric vein resection in pancreatoduodenectomy for pancreatic head carcinoma. Br J Surg. 2015;102(7):837-46. https://doi.org/1 0.1002/bjs.9799.

24. Beane JD, House MG, Pitt SC, Zarzaur B, Kilbane EM, Hall BL, et al. Pancreatoduodenectomy with venous or arterial resection: a NSQIP propensity score analysis. HPB (Oxford). 2017;19(3):254-63. https://doi.org/1 0.1016/j.hpb.2016.11.013

25. Van der Gaag NA, Rauws EA, van Eijck CH, Bruno MJ, van der Harst E, Kubben FJ, et al. Preoperative biliary drainage for cancer of the head of the pancreas. N Engl J Med. 2010;362(2):129-37. https://doi.org/10.1056/NEJMoa 0903230.

26. Scheufele F, Schorn S, Demir IE, Sargut M, Tieftrunk E, Calavrezos L, et al. Preoperative biliary stenting versus operation first in jaundiced patients due to malignant lesions in the pancreatic head: a metaanalysis of current literature. Surgery. 2017;161(4):939-50. https://doi. org/10.1016/j.surg.2016.11.001

27. Lee PJ, Podugu A, Wu D, Lee AC, Stevens T, Windsor JA. Preoperative biliary drainage in resectable pancreatic cancer: a systematic review and network meta-analysis. HPB (Oxford). 2018;20(6):477-86. https://doi.org/10.1016/j. hpb.2017.12.007.
28. Eshuis WJ, van der Gaag NA, Rauws EA, van Eijck CH, Bruno MJ, Kuipers EJ, et al. Therapeutic delay and survival after surgery for cancer of the pancreatic head with or without preoperative biliary drainage. Ann Surg. 2010:252(5):840-9. https://doi.org/10.1097/SLA.0b013e3181fd36a2.

29. Shen Z, Zhang J, Chen H, Wang W, Xu W, Lu X, et al. Does pre-operative biliary drainage influence long-term survival in patients with obstructive jaundice with resectable pancreatic head cancer? Front Oncol. 2020;10: 575316. https://doi.org/10.3389/fonc.2020.575316.

30. Sun C, Yan G, Li Z, Tzeng CM. A meta-analysis of the effect of preoperative biliary stenting on patients with obstructive jaundice. Medicine. 2014;93(26): e189. https://doi.org/10.1097/MD.0000000000000189.

31. Moole $H$, Bechtold M, Puli SR. Efficacy of preoperative biliary drainage in malignant obstructive jaundice: a meta-analysis and systematic review. World J Surg Oncol. 2016;14(1):182. https://doi.org/10.1186/s12957-0160933-2.

32. Yekebas EF, Bogoevski D, Cataldegirmen G, Kunze C, Marx A, Vashist YK, et al. En bloc vascular resection for locally advanced pancreatic malignancies infiltrating major blood vessels: perioperative outcome and long-term survival in 136 patients. Ann Surg. 2008;247(2):300-9. https://doi. org/10.1097/SLA.0b013e31815aab22.

33. Yu XZ, Li J, Fu DL, Di Y, Yang F, Hao SJ, et al. Benefit from synchronous portal-superior mesenteric vein resection during pancreaticoduodenectomy for cancer: a meta-analysis. Eur J Surg Oncol. 2014;40(4):371-8. https://doi. org/10.1016/j.ejso.2014.01.010.

34. Tewari M. Significance of pathological positive superior mesenteric/portal venous invasion in pancreatic cancer. Hepatobiliary Pancreat Dis Int. 2016; 15(6):572-8. https://doi.org/10.1016/S1499-3872(16)60156-X.

35. Martin D, Petermann D, Fontanella S, Pu Y, Halkic N, Demartines N, et al. Pancreatic adenocarcinoma with histologically proven portal vein infiltration: what is the outcome? Eur J Gastroenterol Hepatol. 2018;30(12): 1507-13. https://doi.org/10.1097/MEG.0000000000001266.

36. Roch AM, House MG, Cioffi J, Ceppa EP, Zyromski NJ, Nakeeb A, et al. Significance of portal vein invasion and extent of invasion in patients undergoing pancreatoduodenectomy for pancreatic adenocarcinoma. J Gastrointest Surg. 2016;20(3):479-87. https://doi.org/10.1007/s11605-015-3005-y.

37. Hoshimoto S, Hishinuma S, Shirakawa H, Tomikawa M, Ozawa I, Wakamatsu $\mathrm{S}$, et al. Reassessment of the clinical significance of portal-superior mesenteric vein invasion in borderline resectable pancreatic cancer. Eur J Surg Oncol. 2017;43(6):1068-75. https://doi.org/10.1016/j.ejso.2017.03.020.

38. Ravikumar R, Sabin C, Abu Hilal M, Al-Hilli A, Aroori S, Bond-Smith G, et al. Impact of portal vein infiltration and type of venous reconstruction in surgery for borderline resectable pancreatic cancer. Br J Surg. 2017;104(11): 1539-48. https://doi.org/10.1002/bjs.10580.

39. Addeo P, Velten M, Averous G, Faitot F, Nguimpi-Tambou M, Nappo G, et al. Prognostic value of venous invasion in resected T3 pancreatic adenocarcinoma: depth of invasion matters. Surgery. 2017;162(2):264-74. https://doi.org/10.1016/j.surg.2017.03.008.

40. Ohgi K, Yamamoto Y, Sugiura T, Okamura Y, Ito T, Ashida R, et al. Is pancreatic head cancer with portal venous involvement really borderline resectable? Appraisal of an upfront surgery series. Ann Surg Oncol. 2017; 24(9):2752-61. https://doi.org/10.1245/s10434-017-5972-6.

41. Marsoner K, Langeder R, Csengeri D, Sodeck G, Mischinger HJ, Kornprat $P$. Portal vein resection in advanced pancreatic adenocarcinoma: is it worth the risk? Wien Klin Wochenschr. 2016;128(15-16):566-72. https://doi.org/10.1 007/s00508-016-1024-7.

42. Ravikumar R, Holroyd D, Fusai G. Is there a role for arterial reconstruction in surgery for pancreatic cancer? World J Gastrointest Surg. 2013;5(3):27-9. https://doi.org/10.4240/wjgs.v5.i3.27.

43. Alemi F, Alseidi A, Scott Helton W, Rocha FG. Multidisciplinary management of locally advanced pancreatic ductal adenocarcinoma. Curr Probl Surg. 2015;52(9):362-98. https://doi.org/10.1067/j.cpsurg.2015.07.003.

44. Delpero JR, Sauvanet A. Vascular resection for pancreatic cancer: 2019 French recommendations based on a literature review from 2008 to 6-2019. Front Oncol. 2020;10:40. https://doi.org/10.3389/fonc.2020.00040.

\section{Publisher's Note}

Springer Nature remains neutral with regard to jurisdictional claims in published maps and institutional affiliations. 